This item was submitted to Loughborough's Research Repository by the author.

Items in Figshare are protected by copyright, with all rights reserved, unless otherwise indicated.

\title{
Avoidance and aggregation create consistent egg distribution patterns of congeneric caddisflies across spatially variable oviposition landscapes
}

PLEASE CITE THE PUBLISHED VERSION

https://doi.org/10.1007/s00442-019-04587-7

\section{PUBLISHER}

Springer Science and Business Media LLC

\section{VERSION}

AM (Accepted Manuscript)

\section{PUBLISHER STATEMENT}

This is a post-peer-review, pre-copyedit version of an article published in Oecologia. The final authenticated version is available online at: https://doi.org/10.1007/s00442-019-04587-7

\section{LICENCE}

CC BY-NC-ND 4.0

\section{REPOSITORY RECORD}

Lancaster, Jill, Barbara J Downes, Rebecca E Lester, and Stephen Rice. 2020. "Avoidance and Aggregation Create Consistent Egg Distribution Patterns of Congeneric Caddisflies Across Spatially Variable Oviposition Landscapes". Loughborough University. https://hdl.handle.net/2134/13232285.v1. 
3 Avoidance and aggregation create consistent egg distribution patterns of congeneric caddisflies across

$4 \quad$ spatially variable oviposition landscapes

$7 \quad{ }^{a}$ Jill Lancaster ${ }^{1}$, Barbara J. Downes ${ }^{1}$, Rebecca E. Lester ${ }^{2}$ and Stephen P. Rice ${ }^{3}$

$9{ }^{1}$ School of Geography, University of Melbourne, 221 Bouverie Street, Parkville, Victoria 3010, Australia

$10{ }^{2}$ Centre for Regional and Rural Futures, Deakin University, Locked Bag 20000, Geelong, Victoria 3220,

$11 \quad$ Australia

$12{ }^{3}$ Department of Geography, Loughborough University, Loughborough, Leicestershire, UK

13 LE11 3TU

14

15

Correspondence to: Dr Jill Lancaster 221 Bouverie Street, Parkville, Victoria 3010, Australia email: JillL@unimelb.edu.au

\footnotetext{
a Declaration of authorship: All authors conceived and designed the study. JL, BD and RL collected the data. JL carried out the numerical analyses. JL and BD led the data interpretation and writing. All authors contributed critically to writing the paper and approved the final draft.
} 


\section{Abstract}

Amongst oviparous animals the spatial distribution of individuals is often set initially by where females lay eggs, with potential implications for populations and species coexistence. Do the spatial arrangements of oviposition sites or female behaviours determine spatial patterns of eggs? The consequences of spatial patterns may be context independent if strong behaviours drive patterns; context dependent if the local environment dominates. We tested these ideas using a guild of stream-dwelling caddisflies that oviposit on emergent rocks, focussing on genera with contrasting behaviours. In naturally-occurring oviposition landscapes (riffles with emergent rocks) we surveyed the spatial arrangement and environmental characteristics of all emergent rocks, identified and enumerated egg masses on each. Multiple riffles were surveyed to test for spatially-invariant patterns and behaviours. In landscapes, we tested for spatial clumping of oviposition sites exploited by each species and for segregation of congeneric species. At oviposition sites, we characterised the frequency distributions of egg masses and tested for species associations. Genus-specific behaviours produced different spatial patterns of egg masses in the same landscapes. Congregative behaviour of Ulmerochorema spp. at landscape scales and an aggregative response at preferred oviposition sites led to clumped patterns, local aggregation and species overlap. In contrast, avoidance behaviours by congeners of Apsilochorema resulted in no or weak clumping, and species segregation in some landscapes. Spatial patterns were consistent across riffles that varied in area and oviposition site density. These results suggest that quite different oviposition behaviours may be context-independent, and the consequences of spatial patterns may be spatially invariant also.

Key words: aquatic insects, congregation, rivers, spatial pattern formation, Trichoptera

\section{Introduction}

A long-standing challenge in ecology is to elucidate the causes and consequences of spatial patterns in ecological systems. The spatial distribution of individuals within populations can have consequences for population dynamics (Morris et al. 1992), predator-prey dynamics (Huffaker 1958) and species coexistence 
(Atkinson and Shorrocks 1984; Ives 1988). Mechanistically, spatial aggregation, for example, can exacerbate density-dependent process (e.g. local competition and predation) and density-independent effects (e.g. local disturbance) that potentially reduce fitness. The underlying causes of spatial patterns are also diverse and may include species responses to environmental heterogeneity in resources, how species interact with patchy landscapes (e.g. during movement) and interact with one another. If the consequences of spatial patterns have positive effects on fitness, then heritable variations in behaviour that underpin these patterns should be selected and can result in fixed or intrinsic behaviours (e.g. Vertacnik and Linnen 2017). Although empirical and modelling studies have illustrated the importance of spatial patterns to various ecological processes (references above), less attention is given to whether the behaviours and the spatial patterns they produce are context-dependent.

One challenge for empirical research on the spatial distribution of individuals within populations is to identify useful species and which life cycle stages to examine. Great insights may come from studying life stages where it is possible to quantify survivorship or reproduction, because they influence fitness (Chesson 2008) and spatial patterns of that life stage are likely to influence population dynamics. Oviparous animals, such as insects, can be model systems because egg-laying rate (i.e. birth rate) and the spatial arrangement of eggs at the start of the life cycle may persist through subsequent life stages, and the consequences could also ripple through the life cycle. Females of many species select where they lay eggs and the quality of oviposition sites can have fitness consequences, particularly if all eggs are laid in a single clutch (Refsnider and Janzen 2010). Multiple species can share oviposition sites (e.g. mushrooms, fruits, carcases), which can lead to competition and mortality among their larvae (Ives 1991; Heard 1998), so behaviours or interactions among females that influence the spatial distribution of eggs could affect population dynamics.

Although theory and evidence suggest significance ecological consequences for the spatial distribution patterns of insect eggs, the behaviours that lead to particular spatial patterns are poorly understood. Similarly, it is unclear whether behaviours and egg distribution patterns differ between landscapes that vary in the density or distribution of oviposition patches that females must locate. This is important because models describing the consequences of spatial patterns (e.g. species coexistence models) 
should apply in diverse locations if patterns and the processes of pattern formation are context independent (i.e. do not vary with landscape structure). Models may be more difficult to apply if spatial patterns are context dependent. This could arise if female behaviours vary with environmental characteristics (e.g. movement and search behaviours, Körösi et al. 2008; Schultz et al. 2012) such that egg distribution patterns are contingent upon the density or spatial arrangement of oviposition patches (e.g. Doak 2000). Contextdependent distribution patterns could also arise if pattern formation depends on female abundance (supplyside effects), especially if behaviours and interactions are density-dependent. Even simple behaviours could produce egg distribution patterns that are context sensitive. In an aggregative response, for example, eggs may be aggregated if patches vary in attractiveness (quality) or are more easily found (apparency), such that the degree of aggregation depends on the densities of attractive or apparent patches (Kouki 1991; Heard 1998). Alternatively, aggregation can arise from congregative behaviour of females that oviposit on or close to patches where conspecifics have already laid eggs. Congregative behaviour could be fixed if there are strong benefits to females, eggs or larvae, e.g. via predator swamping or increased egg hatch success (Desurmont and Weston 2011), and the degree of aggregation may not vary between landscapes. Of course, females may also avoid one another during oviposition, which could preclude aggregations but also produce context-independent patterns. Critically, testing for context sensitivity in behaviours and spatial patterns requires multiple landscapes encompassing a wide range of environmental characteristics and species abundances, and with natural distributions of patches (Heard 1998) rather than manipulated landscapes or 'garden' experiments. Such tests are rare, yet in their absence it is difficult to confidently identify causes of patterns in natural landscapes.

Much research on oviposition has been conducted on terrestrial insects, especially herbivores that lay eggs on plants that supply food for offspring (Gripenberg et al. 2010) or parasitoids on animal hosts (Hassell and Pacala 1990), but only rarely have such studies included exhaustive and spatially explicit surveys of all egg masses across multiple natural landscapes (for an exception, see Fagan and Folarin 2001). Alternatively, multiple, naturally variable oviposition landscapes with $10 \mathrm{~s}-100$ s of discrete oviposition patches per landscape occur in rivers and are exploited by multiple co-occurring species of stream insects. Because egg 
abundance directly affects population dynamics, these are ideal systems to test hypotheses about the causes and consequences of spatial distribution patterns. Species in one diverse guild of aquatic insect lay their eggs as single clutches exclusively on the underside of rocks that emerge above the water's surface, which we call emergent rocks. Emergent rocks are therefore essential resources that are patchily distributed along streams in accordance with geomorphological and hydrological processes within river channels (e.g. emergent rocks are more abundant in riffles than pools). Additionally, larger-scale deviations in geology and fluvial geomorphology produce between-river variations in emergent rock patterns. The density of oviposition sites can constrain population size for insects that lay eggs in this manner, because egg supply can be limited by the supply of oviposition sites (Peckarsky et al. 2000; Lancaster et al. 2010a; Lancaster et al. 2010b), with secondary effects on densities of subsequent larval stages (Lancaster et al. 2011; Encalada and Peckarsky 2012; Lancaster and Downes 2014a). Any consequences of spatial patterns are likely to be conspicuous in systems where constraints on population size occur during the life stage involved in the spatial pattern. These species afford an opportunity to test hypotheses about the causes of spatial patterns that can be difficult to test in other systems.

We documented patterns of oviposition for co-occurring and potentially competing, stream-dwelling insects (caddisflies, order Trichoptera) in multiple, natural oviposition landscapes. We then tested hypotheses regarding the behavioural processes that generate patterns, and whether patterns varied with landscape characteristics (i.e. context dependency) and female abundance. The aims were to describe the patterns in a way that allowed us to deduce the underlying behavioural mechanisms. Ovipositing caddisflies are difficult to observe because the adults are predominantly nocturnal and lay eggs underwater. The egg masses of many species can be identified in the field (Lancaster and Glaister 2019), however, so we can describe spatial patterns and infer which behaviours influence pattern formation. Our study organisms were congeneric pairs of caddisfly species in the genera Ulmerochorema and Apsilochorema (family Hydrobiosidae), which cooccur and oviposit contemporaneously on emergent rocks (Reich and Downes 2003a; Reich 2004). There is

124 little overlap in the environmental characteristics of preferred oviposition sites for these genera (Lancaster et 
congeneric species. Thus, the behaviours underlying spatial patterns were compared between genera exploiting slightly different resources, and between congeners exploiting very similar resources. Competition for oviposition sites could be high within these genera because population sizes may be constrained by oviposition site densities (Bovill 2013; Lancaster and Downes 2018). For these four species, oviposition landscapes are spatially discrete riffles, where the water is shallow and emergent rocks (i.e. oviposition sites) are more abundant than in the adjacent pools. We surveyed 18 separate riffles spread across three rivers. For each riffle, egg mass distribution patterns were characterized at the landscape (riffle) scale and oviposition site scale, for each species and potentially interacting species pairs. Egg distribution patterns that are contingent upon landscape characteristics could, theoretically, arise through either fixed or flexible behaviours, depending on the nature of the behaviour. However, if behaviours are contingent upon landscape characteristics or female density, then it seems likely that distribution patterns should be context-dependent. The possible outcomes (combinations of egg distribution patterns at these two scales) and pattern variations are numerous so we reserve our interpretations of observed patterns for the Discussion.

\section{Methods}

\section{Framework for hypothesis tests and interpretations}

The overall objective was to test whether egg mass distribution patterns and the behaviours underlying those patterns differed between oviposition landscapes. In two behavioural contexts (intra- and inter-specific interactions), we posed three kinds of question about the distribution of egg masses, which led to a complex set of data and statistical tests. This overview of the hypothesis framework illustrates how the questions complement one another and how various female behaviours (e.g. avoidance, congregation) may lead to distinct spatial patterns. The first question focussed on species-specific preferences for oviposition habitats according to their local environment. The next two questions about spatial patterns were considered in the same sequence that females follow when deciding where to lay eggs: first at the landscape (riffle) scale and then at the scale of individual oviposition sites (emergent rocks). 
For each species we asked:

(Q1a) Do females exploit oviposition sites with particular environmental characteristics?

(Q2) How does the spatial arrangement of exploited oviposition sites within a landscape compare to the background arrangement of all suitable oviposition sites?

(Q3) What is the frequency distribution of egg masses across suitable oviposition sites?

The environmental characteristics of oviposition sites exploited by each species were identified first (Q1a), and this information was used in subsequent questions about spatial patterns. Non-random spatial arrangements of exploited oviposition sites (Q2) may arise from female behaviours during site selection. Exploited oviposition sites that are clumped together may reflect congregation (e.g. oviposition swarms), whereas even spacing might reflect intraspecific avoidance. At the oviposition site scale, Q3 asks similarly whether egg masses are aggregated onto relatively few oviposition sites (e.g. congregation), or underdispersed across proportionately more sites (e.g. avoidance).

For potentially interacting pairs of congeneric species we asked:

(Q1b) Do congeneric females exploit oviposition sites with similar environmental characteristics? next two questions ask whether there is evidence of spatial resource partitioning at the landscape scale (Q4) or oviposition site scale (Q5). Interspecific avoidance might be manifest as spatial segregation of exploited oviposition sites at the riffle scale (e.g. oviposition sites exploited by conspecifics are closer together than expected by chance, ESM-1), or as negative interspecific association at the site scale (e.g. congeners rarely exploit the same oviposition site).

\section{Study organisms}

177 Our study organisms were four species of caddisflies in two genera of the family Hydrobiosidae. 
Hydrobiosids are common in rivers and streams in Australia and New Zealand (Neboiss 1986), where their aquatic larvae pass through five instars before pupating and emerging as terrestrial, winged adults. This study focussed on two genera, Ulmerochorema and Apsilochorema, and two species within each genus that cooccurred in our study area: U. rubiconum (Neboiss), U. seona (Mosely), A. obliquum (Mosely), A. gisbum

182 (Mosely). Various aspects of oviposition in these genera have been reported previously (Lancaster et al. 2003; Reich and Downes 2003a; Reich and Downes 2003b; Bovill et al. 2013; Bovill et al. 2015), but this is the first study to examine species-level patterns and behavioural interactions across multiple riffles and rivers. All four species have the same mode of oviposition: a gravid female first lands on the surface of an emergent rock, then walks down the side into the water and lays her eggs in a single, gelatinous masses on the underside of the rock. Oviposition on emergent objects other than rocks (e.g. woody debris) is rare in our system. These species lay eggs throughout the year in our study sites, but most frequently in the warm months (Lancaster unpublished data). Typically, eggs hatch within 2-3 weeks in most seasons but may take up to 4 weeks in cold winter months. Larvae of all instars occur in the benthos throughout the year. Neonates and later instar larvae are free-living and able to roam freely, but details of their movement behaviours are largely unknown. Gut contents analyses indicate that all instars are carnivorous (Lancaster unpublished data).

\section{Study sites}

Our surveys were carried out during a 3-week period from mid-January to early February 2017, in three rivers in Victoria, Australia. Survey riffles were selected from within a 1-km length of each river: Snobs Creek, Little River and Steavenson River. Similar altitudes, water temperatures and geographical proximity ensured similar climatic conditions and a similar regional species pool (ESM-2). Insect populations within these river lengths were largely isolated by high ridges between river valleys, and this separation of populations facilitates robust hypothesis tests. The study lengths had largely intact riparian vegetation and were broadly similar in size and geomorphological character. However, they did differ in ways that may be relevant to ovipositing insects (ESM-2), so between-river differences in insect behaviour and egg distribution-patterns are possible. Riffles in each river were selected to encompass a wide range of sizes 
204 (length and area) and emergent rock densities $\left(0.40-4.32 \mathrm{~m}^{-2}\right.$, ESM-3), in order to capture the natural range 205 of conditions. We could not select riffles according to female abundance, but egg mass densities (a proxy 206 measure of female density), spanned at least an order of magnitude over the sample riffles for each species

207 (ESM-3), suggesting that these riffles encompassed a wide range of female abundances. Riffles were lengths 208 of river channel created by abrupt increases in channel slope, with emergent rocks that would serve as 209 potential oviposition sites, and bounded upstream and downstream by channel lengths with few or no 210 emergent rocks. Thus, they represent fairly discrete units of habitat containing multiple resource patches 211 (emergent rocks) and surrounded by areas with few resource patches.

\section{$213 \quad$ Field survey protocols}

214 Each riffle was surveyed once and in each survey we mapped the spatial coordinates (X, Y) of every potential 215 oviposition site, mapped the riffle perimeter, and calculated riffle area using a total station (Leica TC803). 216 Potential oviposition sites were emergent rocks (ERs) that were $\geq 5 \mathrm{~cm}$ in size (b-axis dimension), in $\geq 5 \mathrm{~cm}$ 217 of water and not embedded in fine sediments, because previous work showed that caddisflies rarely lay eggs on small rocks in shallow water (Reich and Downes 2003a; Lancaster et al. 2010b). The egg masses (EMs) of all caddisfly species were counted and identified on every ER; only results for species of Apsilochorema and Ulmerochorema are reported here. For each ER, we measured several physical variables in a similar manner to previous surveys (Lancaster et al. 2003; Reich and Downes 2003a): water velocity upstream of the rock, rock size (b-axis dimension, Gordon et al. 2004), water depth downstream of the rock, and the height of the rock projecting above the water surface. Velocity was measured near the stream bed using an electromagnetic current meter (Valeport Model 801), fit with a single axis flat sensor, which is suitable for measuring flow in water depths $\geq 6 \mathrm{~cm}$.

\section{Numerical analyses}

Questions 1-5, posed above, required different forms of data analysis, which are described below. Pattern consistency across riffles was assessed in the context of each question. 
(Q1a\& 1b) Environmental characteristics of oviposition sites.

232 For each river, we pooled the data over all riffles and used MANOVA with planned contrasts to test, for each species, whether characteristics of emergent rocks (water depth, velocity, rock size and exposed height) differed between those with and without egg masses (Q1a). We also tested whether the characteristics of ERs exploited by species in a congeneric pair differed from one another (Q1b). These analyses defined exploited ERs by the presence of EMs, not the number of EMs. The nature of our survey data deviated from some underlying assumptions of MANOVA but these deviations were minor and did not influence interpretation of the results $(\mathrm{ESM}-4)$.

Different statistical models were used for the two genera. A two-way orthogonal MANOVA was used for Apsilochorema spp., with each ER classified according to two crossed factors: presence $v s$ absence of EMs of A. obliquum, and of A. gisbum. If the interaction term in this test is not significant, then the main effects indicated whether ERs with and without EMs differed in character for each species, and planned contrasts tested whether the congeners selected different kinds of ERs. If the interaction term was significant, then planned contrasts tested whether ERs exploited by each species differed from ERs exploited by neither, and whether congeners selected different kinds of ERs. Note, the interaction term itself is not germane to the hypotheses of interest. Tests for Ulmerochorema spp. were different because very few rocks had only EMs of U. seona, i.e. exploited ERs either had EMs of U. rubiconum only, or both species. Accordingly, these data were analysed with a one-way MANOVA with three treatments (no EMs, EMs of U. rubiconum only, and EMs of both species), and planned contrasts were used for all hypothesis tests.

(Q2) How does the spatial arrangement of exploited oviposition sites compare to the background of all suitable oviposition sites?

The spatial distributions of exploited ERs were compared to random selections of suitable ERs using point process statistics in which ERs are assumed to be points with $\mathrm{X}-\mathrm{Y}$ coordinates within a polygonal-shaped window bounded by the edges of the riffle. Our numerical analyses were based on the Ripley's $K(t)$ function 
and its linear transformation $L(t)$ (Ripley 1976; Besag 1977), which can detect clumping or even spacing of points. Our approach followed the logic used in previous studies for tests using emergent rocks or leaf packs in rivers (Lancaster et al. 2003; Lancaster and Downes 2014b). The null hypothesis was not a random arrangement of exploited ERs in the riffle, because insects can only select ERs that exist and their positions were fixed. Instead the existing spatial arrangement of suitable ERs formed the null or neutral landscape (With and King 1997) and we tested whether observed distributions of exploited ERs were random selections of the suitable ERs (see ESM-5 for definitions and data on suitable ERs). These analyses were restricted to riffles with at least 15 exploited ERs and where at least $50 \%$ of all suitable ERs were unexploited. If the number of exploited ERs is too small, it is difficult to establish a clear pattern. If the proportion of suitable but unexploited ERs is too small, permutation tests of statistical significance are not feasible. Analyses were carried out in R (version 3.4.0) (R Core Development Team 2017) and used functions in the package 'spatstat' (version 1.52-1) (Baddeley et al. 2016).

Point pattern description: The second-order $L(t)$ function is the cumulative distribution function of all point-to-point distances in relation to distance $t$. Patterns were examined over relatively small scales of $t \leq$ $3 \mathrm{~m}$ (less than half the stream width for most of our riffles), because insect behaviours that influence egglaying patterns are likely to play out over small scales. The $L$-function assumes that the point process is firstorder stationary, i.e. that the density or intensity of points is spatially homogeneous. The physical processes that determine the arrangement of ERs in rivers result in patterns that are not stationary (Lancaster et al. 2003), so analyses used an inhomogeneous $L$-function, $L I(t)$ (Baddeley et al. 2000), and the spatial variation in point intensity was estimated as a kernel-smoothed intensity function using the 'density' function in 'spatstat'. Edge correction was not used because our data formed finite point processes in which points cannot exist outside the boundary, i.e. ERs cannot occur beyond the stream banks or ends of the riffle (e.g. Lancaster et al. 2003; Lancaster and Downes 2004).

Statistical tests: For each species we tested whether the pattern of exploited ERs was independent of the underlying pattern of all suitable ERs, i.e. whether exploited ERs were a non-random selection of all suitable ERs. The locations of suitable ERs were fixed and these points were marked according to egg mass 
282 presence/absence (a multi-type point pattern). Hypothesis tests involved comparing the $L I$-function of exploited ERs, $L I(t)_{\mathrm{Obs}}$, with the $L I$-function of a random selection of the same number of suitable ERs, $L I(t)_{\mathrm{Ran}}$. The null hypothesis (exploited ERs are a random selection of ERs) is indicated if $L I(t)_{\mathrm{Obs}}-L I(t)_{\mathrm{Ran}}=$ 0 (Lancaster et al. 2003; Lancaster and Downes 2004; Warren-Rhodes et al. 2007). Following recent guidelines (Baddeley et al. 2014), we used a global envelope test (also called a maximum absolute deviation test) to infer statistical significance. This is a conservative test, but avoids some problems interpreting tests using the commonly used pointwise envelope. First, a point-wise $95 \%$ confidence interval around the mean difference was calculated from 99 Monte Carlo permutations of presence/absence marks. The most extreme deviation over the entire range of $t$ was used to create a global confidence envelope of constant width around the mean difference. If values of the mean difference and its envelope are positive (i.e. $\left.L I(t)_{\text {Obs }}-L I(t)_{\text {Ran }}>0\right)$ over any values of $t$, this suggests that exploited ERs are more clumped than the underlying pattern; conversely, negative values of the mean and its envelope suggest an even distribution relative to the underlying pattern.

\section{(Q3) What is the frequency distribution of egg masses across suitable oviposition sites?}

We used a goodness-of-fit test (G-test) to compare the observed frequency distribution of egg masses per ER with that expected for a random distribution based on a zero-truncated Poisson distribution. Separate tests were carried out for each species and river, with data pooled across all riffles in each river to ensure adequate sample sizes. The zero-truncated Poisson distribution is a parsimonious test that avoids biasing the outcome by including many unsuitable ERs that have no EMs (Lancaster et al. 2010a), which can occur in tests based on the coefficient of dispersion. A significant G-test (EMs are not randomly distributed across ERs) could reflect one of two patterns. Egg masses could be aggregated (a contagious distribution) if ERs with many EMs occur more frequently than expected by chance, such that most EMs occur on just a few ERs, which have very high EM densities. Conversely, EMs could be under-dispersed (a regular distribution) if the number of ERs with only one or a few EMs is greater than expected by chance, such that the majority of all EMs occur on a disproportionately large number of ERs, which have low densities. For significant G-tests, 
aggregated or under-dispersed patterns were determined by examining whether the majority of EMs occurred on proportionately many $v s$ few ERs.

(Q4) Is the spatial arrangement of oviposition sites exploited by one species independent of its congener?

312 To test whether behavioural interactions between congeners when selecting oviposition sites influenced spatial patterns, we extended our methods of point pattern analyses described in Q2. We used the bivariate $L$ function, $L_{i j}(t)$, also called the cross-type $L$-function. Bivariate tests were only possible for Apsilochorema spp. because few ERs had egg masses of Ulmerochorema seona only. Statistical tests using the bivariate $L_{i j}{ }^{-}$ function were essentially a test of random labelling (Baddeley et al. 2016) and followed procedures analogous to those described above for the univariate patterns (Q2). The null hypothesis is indicated if $L_{i j}(t)_{\text {Obs }}-L_{i j}(t)_{\text {Ran }}=0$, where $L_{i j}(t)_{\text {Obs }}$ is the bivariate function of observed data, and $L_{i j}(t)_{\text {Ran }}$ is calculated from a random labelling of points. Global envelopes were calculated, as above, to infer statistical significance. If $L_{i j}(t)_{\mathrm{Obs}}-L_{i j}(t)_{\mathrm{Ran}}>0$ this suggests segregation of the two species, i.e. ERs exploited by the same species were closer together than expected and, conversely, if $L_{i j}(t)_{\mathrm{Obs}}-L_{i j}(t)_{\mathrm{Ran}}<0$ then ERs exploited by different species were closer together than expected.

(Q5) Do congeners exploit the same oviposition site more or less often than expected by chance?

First, the proportions of ERs exploited by both species or by only one species were calculated. Then, we used a modified form of Sørenson's coefficient to describe the proportion of individual egg masses that occurred together (Southwood 1978). This coefficient ranges from -1 (complete negative association) to +1 (complete positive association). A negative association could arise if congeners avoid one another; a positive association could arise if there is attraction (e.g. congregation). This index was calculated for each riffle in each river, with ANOVA to test for differences between rivers and $t$-tests to determine whether values of the index differed from zero.

\section{Results}


334 Rivers differed in the range of environmental characteristics of emergent rocks; minimum values were similar 335 in all rivers and the main differences lay in the high values (ESM-2). The rank order of rivers was Snobs Ck

336 > Little R. > Steavenson R. in terms of the median and maximum values of all four variables: water velocity, 337 water depth, rock size and exposed rock height.

(Q1a \& 1b) Do species select oviposition sites with particular environmental characteristics? Do congeners select different kinds of oviposition sites?

For all four species, MANOVA indicated that ERs with and without egg masses differed in their environmental characteristics in most rivers (Tables 1,2). One exception, Apsilochorema gisbum in Snobs $\mathrm{Ck}$, was marginally non-significant $(P=0.098)$. The two species of Apsilochorema did not differ from one another in their choice of oviposition site characteristics in any river, whereas the congeners of Ulmerochorema differed in all rivers. Although the collective effects of all environmental variables were tested within a MANOVA, the relative strengths of different variables can be inferred from the univariate $F$ tests within the MANOVA (ESM-6). Compared to the range of ERs available, both species of Apsilochorema generally selected large ERs in deep water that protruded high above the water surface and velocity was a weaker predictor of oviposition site selection (Fig. 1). In contrast, both species of Ulmerochorema were strongly influenced by all environmental variables and tended to select large ERs in fast flowing, deep water that protruded high above the water surface (Fig. 1). The two congeners differed from one another in that U. rubiconum exploited ERs with a wide range of environmental characteristics whereas U. seona was restricted to a subset of the ERs exploited by U. rubiconum. Specifically, U. seona tended to exploit the largest ERs in the fastest flows and deepest water. There was no correlation between the number of egg masses of U. rubiconum and U. seona on individual ERs, regardless of whether the tests included all ERs with any EMs of Ulmerochorema (Little R.: $r_{242}=0.115, P=0.073$; Snobs Ck: $r_{105}=0.154$, $P=0.113$ ) or only ERs with EMs of both species (Little R.: $r_{60}=0.151, P=0.241$; Snobs Ck: $r_{23}=0.037, P$ $=0.861)$. Calculating effect sizes is difficult in a MANOVA, which simultaneously considers multiple 
dependent variables, but the test outcomes for the hypotheses of interest were generally clear cut ( $P$-values $\leq$ $0.001)$ and patterns were consistent across rivers.

(Q2) How does the spatial arrangement of exploited oviposition sites compare to the background of all suitable oviposition sites?

In most riffles, ERs exploited by congeners of Ulmerochorema were spatially clumped relative to the distribution of suitable ERs, whereas ERs exploited by Apsilochorema were distributed randomly in most riffles, with a few clumped patterns (Table 3, Fig. 2). Ulmerochorema seona was sufficiently abundant for univariate PPA tests in only one riffle, which showed a clumped pattern. Clumping was statistically significant in nine of the 12 riffles for $U$. rubiconum; the remaining three were random patterns. Riffles with clumped patterns had significantly higher egg mass densities $\left(\mathrm{N} \mathrm{m}^{-2}\right)$ than those with random patterns $\left(t_{4}=\right.$ 3.34. $P=0.015$, using log-transformed densities in riffles of the Little R.). These were one-tailed tests because we were only interested in whether clumping might relate to high female abundance. Patterns were generally random for the congeners of Apsilochorema, with clumping in one out of eight riffles for $A$. obliquum, and two out of seven for A. gisbum. As with Ulmerochorema, riffles with significantly clumped patterns had higher densities of egg masses $\left(t_{3}=3.04, P=0.028 ; t_{3}=2.78, P=0.035\right.$, for $A$. obliquum and $A$. gisbum respectively, one-tailed $t$-tests as above). There was no consistency in which rivers showed random or - $L I_{\text {ran }}(t)$, all showed a step increase at $t \approx 0.38 \mathrm{~m}$ (Fig. $\left.2 \mathrm{~b}, 2 \mathrm{~d}\right)$. This is could be evidence of clumping at very small scales, or an artefact because ERs form a hard core point process in which even tightly packed rocks must be some minimum distance apart (Baddeley et al. 2014). In our riffles, most nearest-neighbour distances were $0.2-0.4 \mathrm{~m}$, coinciding with this step increase at $\approx 0.38 \mathrm{~m}$. Thus, we took a conservative approach and only values of $t \geq 0.5 \mathrm{~m}$ were considered when categorising the spatial pattern of exploited ERs. 
384 Egg masses of Apsilochorema obliquum and A. gisbum were significantly under-dispersed in one and two

385 rivers, respectively (Table 4). In other words, in these rivers the majority of all EMs occurred on ERs that had

386 low egg mass densities for that species. In the Little R. for example, $72 \%$ of the EMs of $A$. obliquum occurred

387 on $90 \%$ of the exploited ERs, and those exploited ERs had densities of $\leq 2$ egg masses per rock. The

388 apparently random patterns in some rivers may result from low degrees of freedom in the G-test (i.e. low

389 power because few rocks had $>2$ egg masses). In contrast, both species of Ulmerochorema were significantly

390 aggregated such that most EMs occurred on relatively few rocks (Table 4). For example, in the Little R., 70\%

391 of egg masses of U. rubiconum occurred on only $30 \%$ of the exploited ERs, and those exploited ERs had

392 densities of $\geq 25$ egg masses per rock.

393

394 (Q4) Is the spatial arrangement of oviposition sites exploited by one species independent of its

\section{5 congener?}

396 Six riffles had adequate numbers of ERs exploited by both species of Apsilochorema to carry out bivariate

397 point pattern analysis: four in the Little R. and two in the Steavenson R. Four of these riffles (three in the

398 Little R., one in Steavenson R.) showed evidence of an interaction between the two species, i.e. non-random

399 labelling of points (example in ESM-7), and the remaining two (one in each river) suggested no interaction.

400 The direction of the significant patterns suggests segregation, i.e. the distance between ERs exploited by the

401 same species was smaller than the distance between ERs exploited by different species (ESM-1). As in Q2,

402 we considered only values of $t \geq 0.5 \mathrm{~m}$ when assessing for evidence of interaction.

403

(Q5) Do congeners exploit the same oviposition site more or less often than expected by chance?

Egg masses of both congeners of Apsilochorema co-occurred on few ERs, whereas EMs of only A. obliquum or only A. gisbum occurred on $\geq 40 \%$ of ERs each (Fig. 3a). In contrast, EMs of both species of

Ulmerochorema occurred on $\approx 25 \%$ of the exploited ERs, most of the remainder held only U. rubiconum, and few had only EMs of $U$. seona (Fig. 3b). Sørenson's coefficient of interspecific association was negative for congeners of Apsilochorema in all rivers (Fig. 3c). For congeners of Ulmerochorema, there was no evidence 
of association (Fig. 3d). Egg masses of $U$. rubiconum were far more abundant than those of $U$. seona and this

411 could make it difficult to detect association.

\section{Discussion}

414 The behaviours of egg-laying females create patterns in the spatial distribution of individuals at the start of 415 the life cycle and these patterns can have implications for population dynamics. In this study of a guild of cooccurring aquatic insects that lay eggs exclusively on emergent rocks in rivers, we found that female behaviours during oviposition were fixed or inflexible, and the resulting egg distribution patterns were relatively invariant across multiple, natural landscapes. Thus, egg mass distribution patterns were generally consistent across multiple riffles in rivers, despite wide and natural variations in riffle size, and in densities of prospective oviposition sites that varied over an order of magnitude. Patterns were most apparent where gravid females were abundant, but there was no compelling evidence to suggest that behaviours and egg distribution patterns varied with female density. Such invariant or context-independent patterns and fixed oviposition behaviours can arise when there are strong fitness benefits (Vertacnik and Linnen 2017). Furthermore, we found different behaviours (congregation vs avoidance) for congeneric species pairs, which produced different distribution patterns of egg masses in the same landscapes (strong aggregation $v s$ segregation), yet behaviours and patterns were still context-independent. Our ability to detect such patterns and gain insight into their prospective causes was enabled by a spatially-explicit approach with complementary tests addressing different aspects of species' behaviour that manifest at different scales, and by large sample sizes. With fewer landscapes (riffles), it is doubtful that we would have uncovered some patterns and had confidence that they are ecologically meaningful rather than chance events. The use of ecologically relevant neutral landscapes in hypothesis tests was also pivotal in providing ecologically meaningful inferences about behaviours, even though some landscapes were not amenable to all tests. landscapes means that models predicting the consequences of egg distribution (e.g. species coexistence 
species interact with one another and their environment can vary with environmental characteristics and species' identity (Menge 1976; McPeek 2017; references above). For example, research on Lepidoptera (a sister order of Trichoptera) that oviposit on food plants suggests that the physical structure of landscapes and the distribution of resources within habitat patches can affect movement behaviours (Schtickzelle et al. 2007; Schultz et al. 2012) and this can lead to landscape-specific patterns in the density and distribution of eggs (Jones 1977; Doak 2000; Körösi et al. 2008). Why egg distribution patterns should be context-dependent for some insects but not others may relate to differences in the nature of oviposition sites (discussed below), but this variation means that the consequences of egg distribution patterns may be more difficult to model or predict.

The characteristics of egg mass distribution patterns and the potential underlying behaviours differed between the genera Apsilochorema and Ulmerochorema, at both the landscape and site scales. These warrant some consideration because particular behaviours or behavioural syndromes may be common to other species and systems where spatial patterns and consequences are also context-independent. We discuss each species pair in turn and then consider potential ecological consequences of the patterns.

For Ulmerochorema, the overall pattern in all landscapes was of highly clumped and aggregated egg masses on selected oviposition sites. The physical characteristics of oviposition sites (emergent rocks, ERs) selected by each species differed from unexploited ERs, differed between the two congeners, and the patterns were consistent across rivers. More interestingly, the ERs exploited by $U$. seona were a near perfect subset of those exploited by $U$. rubiconum, suggesting that $U$. seona has an included niche (sensu Miller 1967). Both species preferred large ERs in fast flowing, deep water, as observed previously for the genus (Lancaster et al. 2003; Reich and Downes 2003a), but U. seona showed a stronger preference for the biggest ERs in the fastest and deepest water. Spatially, the exploited ERs were clumped relative to the background pattern of ERs in $75 \%$ of landscapes. In a minority of riffles, exploited ERs were random and these landscapes were not systematically different in physical character, but egg mass densities were lower, suggesting low statistical power when females were scarce. At the oviposition site scale (individual ERs), the egg masses of both congeners were strongly aggregated with $10 \mathrm{~s}-100$ s of egg masses on some ERs, as found previously 
(Lancaster et al. 2003; Reich and Downes 2003a). We found no evidence of interspecific association (positive

463

464 or negative), although the numerical dominance of $U$. rubiconum may have made it difficult to detect association at the site scale, and bivariate PPA testing for interactions between the two congeners at the landscape scale was not possible.

Congregative behaviour at the landscape (riffle) scale coupled with an aggregative response at the oviposition sites is a parsimonious explanation of the behaviours underlying the egg mass distribution patterns of Ulmerochorema. Spatial clumping could arise if females swarm when laying eggs and, although we lack direct evidence of congregation, adults of both congeners are often numerous in light traps (J. Lancaster, pers. obs.). Aquatic insects can occur in multi-species swarms (Haddow and Corbet 1961), which may contribute to the strong co-occurrence of $U$. rubiconum and $U$. seona. Aggregation pheromones and sex pheromones are well known in insects, including caddisflies (Resh and Wood 1985; Löfstedt et al. 1994), and can result in aggregated oviposition (Anderson 2002). For U. rubiconum, previous research indicated an aggregative response of ovipositing females to the local environment of ERs (Reich et al. 2011), and adults alight more often on ERs in fast than slow flow, suggesting a capacity to detect suitable rocks from the air (Reich and Downes 2003b). Ulmerochorema seona may have a similar aggregative response albeit to a more specific environmental factor or suite of factors, given its more narrow choice of rocks.

In contrast, the egg masses of Apsilochorema spp. were distributed differently and avoidance behaviours may drive these patterns. The preferred oviposition sites of the congeners had identical physical characteristics in all rivers, and they differed from unexploited ERs. These species preferred large ERs in deep water, as reported previously for the genus (Lancaster et al. 2003; Reich and Downes 2003a). Velocity was a good predictor of preferred oviposition sites for Apsilochorema in experiments (Reich and Downes 2003b) and, indeed, the soft jelly of these egg masses cannot withstand the shearing forces of fast flows (Bovill et al. 2013). Weak effects of velocity in this study may be attributed to correlations between rock size and velocity in surveys, which can be de-coupled in experiments. At the scale of individual oviposition sites, egg masses of each congener were under-dispersed (most ERs had only one egg mass), suggesting intraspecific avoidance. In oviposition landscapes, the ERs exploited by each congener were distributed 
randomly relative to background in 12 out of 15 riffles; the remaining three riffles had clumped spatial distributions. There were no obvious differences in the landscape characteristics of riffles with different patterns, but clumped patterns occurred where egg mass densities were the highest, a proxy measure of female density. These clumped patterns at landscape scales are unlikely to be chance events, they are ecologically interesting and could arise from avoidance behaviour at oviposition site scales.

What is the mechanistic basis for the intraspecific avoidance of Apsilochorema spp.? It is unlikely that adult females encounter and avoid one another during oviposition, because egg masses on a single ER could accumulate over several nights and direct encounters between females may be infrequent. It is more likely that females avoid ovipositing on ERs where egg masses of conspecifics are present. A parsimonious process of avoidance could generate the observed spatial patterns: if a female encounters an egg mass of a conspecific on an ER, she then abandons that ER and subsequently exploits another ER nearby. Observations of another species of Hydrobiosidae, Ethochorema turbidum, showed that females can reject oviposition sites and fly to others (Reich 2002). Many insects follow a behavioural sequence of searching and evaluating potential oviposition sites before deciding to accept or reject a particular location, including Lepidoptera (Renwick and Chew 1994). Oviposition-deterrent pheromones in insects can be associated with the eggs directly or with secretions produced during oviposition (Anderson 2002), and can be responsible for underdispersed distributions of eggs (Schoonhoven et al. 1990; Gabel and Thiéry 1992). Adult caddisflies have diverse and numerous sensory receptors, including chemoreceptors, on the tarsi, antennae and other body parts (Melnitsky and Ivanov 2011; Lancaster and Downes 2013), so contact evaluation of egg masses is plausible. This simple form of intraspecific avoidance (abandoning exploited ERs and flying to the nearest available ER) could lead to clumped arrangements of exploited oviposition sites at landscape scales, which we observed in some riffles. For caddisflies, if the females and egg mass densities are high, it is likely that females will encounter egg masses frequently and landscape-scale patterns will be pronounced and easily detected.

Interspecific avoidance by the congeners of Apsilochorema, suggested at both oviposition site and landscape scales, could also arise from similar avoidance behaviours. At oviposition sites, egg masses of 
514 congeners occurred on the same ERs less often than expected (negative association). This can arise though 515 different oviposition site preferences (Lounibos 1981), but these congeners had identical oviposition site 516 preferences, making avoidance more likely. At the landscape scale, bivariate point pattern analyses suggested 517 spatial segregation and hence inter-specific avoidance of $A$. obliquum and A. gisbum in four of the six riffles 518 that we could analyse. Segregation was apparent in riffles with high egg mass densities and random patterns 519 in the minority of riffles may reflect low encounter rates when densities are low. Spatial segregation can be 520 accompanied by clumped spatial arrangements for one or both species (illustrations in ESM-1) and, indeed, 521 the riffles that displayed clumping of single species also displayed segregation of congeners. The intraspecific avoidance behaviour outlined above could also produce inter-specific avoidance if females avoid ERs that have egg masses of either conspecifics or congenerics. The egg masses of these congeners are morphologically similar (Lancaster and Glaister 2019) and it is plausible that contact cues elicit similar behavioural responses from congeners and conspecifics. Inter-specific avoidance via oviposition-deterrent pheromones occurs in insects and can generate characteristic distribution patterns of eggs (Schoonhoven et al. 1990; Gabel and Thiéry 1992). It is notable that spatial clumping and segregation of Apsilochorema spp. was detected at small scales $(\leq 3 \mathrm{~m})$. These scales are pertinent to our proposed avoidance behaviour because a female rejecting one oviposition site is likely to select an alternative site nearby and within the same riffle $(<10 \mathrm{~m})$, rather than travelling farther $(>>10 \mathrm{~m})$ to a different riffle and incurring the risks associated with prolonged flight, e.g. interception by aerial predators (Encalada and Peckarsky 2007). Collectively, these results provide compelling evidence of both intra- and inter-specific avoidance for two species of Apsilochorema at oviposition sites, which may arise from a simple avoidance behaviour and produce distinctive distribution patterns of egg masses in oviposition landscapes. with other systems requires caution, because spatially explicit research on oviposition in natural landscapes is rare (as noted above) and systems can differ in quite significant ways. The dominant literature on insect oviposition focusses on terrestrial, herbivorous insects, which are biologically very different to hydrobiosid caddisflies. Plants can offer multiple cues to searching females, including plant architecture (Mattingly and 
540 Flory 2011) and phytochemicals (Städler 2002), which may be associated with behaviour that is different to 541 caddisflies searching for inert and structurally simple emergent rocks. Additionally, herbivorous insects seek 542 plants that typically provide food for larvae, whereas emergent rocks are not associated with food for 543 predatory larval caddis. Oviposition site choices by hydrobiosids may be associated more strongly with 544 reducing mortality of offspring due to competition or predation, rather than characteristics of the oviposition 545 site itself. Consistent with this notion, reducing predation risks for offspring can influence oviposition site 546 choice by predatory terrestrial insects (Doumbia et al. 1998) and pond-dwelling aquatic insects (Resetarits Jr. 547 2001). However, because stream-dwelling larvae may move long distances from oviposition sites, which 548 themselves may be unrelated to larval habits, it is feasible that pond insects are also not ideal systems for 549 comparison. It is nevertheless intriguing that these caddisflies show such strong oviposition preferences, and 550 fitness consequences seem likely.

551 The spatial patterns observed in this survey suggest intriguing implications for the coexistence of 552 hydrobiosid species. All four study species co-occur in the same riffles, along with several other con-familial 553 species with similar oviposition habits (Lancaster and Glaister 2019) and their larvae form a guild of 554 potentially competing carnivores. Clumped and aggregated distributions of egg masses create aggregations over small areas. In addition, the egg masses of all species that oviposit on ERs will be aggregated relative to total riffle area (e.g. maximum potential habitat for larvae), because ERs are typically clumped within riffles (Lancaster et al. 2003). Egg hatching rates are high for both Ulmerochorema and Apsilochorema (Reich 2004; Bovill et al. 2013) suggesting low egg mortality for these genera (Bovill et al. 2015). Thus, the aggregated distribution of egg masses will result in similarly aggregated groups of neonate larvae comprising 100s-1000s of siblings, conspecifics, congenerics and confamilials. Competition for food may be intense because these neonates have virtually no yolk in the gut (Lancaster pers. obs.), so capturing the first prey item may be critical (Hildrew and Wagner 1992). The avoidance behaviour of Apsilochorema may reduce competition among neonates and also enhance coexistence between Apsilochorema species, e.g. depending on whether inter-specific aggregation of eggs is greater than intra-specific aggregation, which requires consideration of clutch sizes (Ives 1988; Ives 1991). Alternatively, the included niche of U. seona may 
566 suggest either that $U$. seona is a superior competitor to U. rubiconum, or that larvae of both species move

567 rapidly and far away from natal areas upon hatching. Currently, we lack information about the neonate

568 behaviour and further data are needed to elucidate the mechanisms of species coexistence for this intriguing

569 guild of insects.

570 The spatial distribution of individuals is non-random in most ecological systems. This study shows

571 that for some caddisflies the nature of those patterns may not vary between locations that differ naturally in

572 size and the density of resource patches, a marked contrast to the context-dependent patterns suggested for

573 some terrestrial insects. Landscape configuration may influence movement patterns in some systems, but

574 strong preferences for patch quality and strong inter-individual interactions can result in similar spatial

575 distribution patterns of individuals in natural landscapes. Quite different kinds of inter-individual interactions,

576 avoidance and congregation, both created consistent patterns across landscapes in this study. Notably, this

577 suggests that the consequences of particular spatial patterns may be similar in multiple locations, and this

578 now requires specific tests. It is possible that the behaviours driving pattern formation in these caddisflies

579 may be shared by other species and also create context-independent spatial patterns in other systems.

Acknowledgements

This research was supported by a Discovery grant from the Australian Research Council (DP 160102262).

We are deeply indebted to the assistants who helped collect these data: Courtney Cummings, David

Dodemaide, Alena Glaister, Ashley Macqueen and Rafael Schouton. Thanks to Peter Grant for facilitating access to Snobs Ck. Field work was carried out in conjunction with a Research Permit (No. 10007855) under the National Parks Act (Australia), from the Department of Environment, Land, Water and Planning 587 (Victoria).

\section{References}

590 Anderson P (2002) Oviposition pheromones in herbivorous and carnivorous insects. In: Hilker M, Meiners T 591 (eds) Chemoecology of Insect Eggs and Egg Deposition. Blackwell Publishing Ltd, Berlin, pp 235-263 
Atkinson WD, Shorrocks B (1984) Aggregation of larval Diptera over discrete and ephemeral breeding sites: the implications for coexistence. Am. Nat. 124:336-351 doi: 10.1086/284277

Baddeley A, Diggle PJ, Hardegen A, Lawrence T, Milne RK, Nair G (2014) On tests of spatial pattern based on simulation envelopes. Ecol. Monog. 84:477-489 doi: 10.1890/13-2042.1

Baddeley A, Rubak E, Turner R (2016) Spatial Point Patterns: Methodology and Applications with R. Chapman and Hall/CRC Press, Boca Raton, U.S.A.

Baddeley AJ, Møller J, Waagepetersen R (2000) Non- and semi-parametric estimation of interaction in inhomogeneous point patterns. Stat. Neerlandica 54:329-350 doi: 10.1111/1467-9574.00144

Besag J (1977) Contribution to the discussion of Dr Ripley's paper. J. R. Statist. Soc. B 39:193-195

Bovill WD (2013) The recruitment dynamics of stream insect larvae: oviposition and egg mortality of hydrobiosid caddisflies. PhD Thesis, The University of Melbourne, Melbourne, Australia

Bovill WD, Downes BJ, Lancaster J (2013) A test of the Preference-Performance Hypothesis in stream insects: selective oviposition affects the hatching success of caddisfly eggs. Freshwater Biol. 58:22872298 doi: $10.1111 /$ fwb.12209

Bovill WD, Downes BJ, Lancaster J (2015) Caddisfly egg mass morphology mediates egg predation: potential costs to individuals and populations. Freshwater Biol. 60:360-372 doi: 10.1111/fwb.12497

Chesson P (2008) Quantifying and testing species coexistence mechanisms. In: Valladares F, Camacho A, Elosegui A, Gracia C, Estrada M, Senar JC, Gili JM (eds) Unity in Diversity: Reflections on Ecology after the Legacy of Ramon Margalef. Fundacion BBVA, Bilbao, pp 119-164

Desurmont GA, Weston PA (2011) Aggregative oviposition of a phytophagous beetle overcomes eggcrushing plant defences. Ecol. Entomol. 36:335-343 doi: 10.1111/j.1365-2311.2011.01277.x

Doak P (2000) Population consequences of restricted dispersal for an insect herbivore in a subdivided habitat. Ecology 81:1828-1841 doi: 10.1890/0012-9658(2000)081[1828:PCORDF]2.0.CO;2

Doumbia M, Hemptinne J-L, Dixon A (1998) Assessment of patch quality by ladybirds: role of larval tracks. Oecologia 113:197-202 
617 Encalada AC, Peckarsky BL (2007) A comparative study of the costs of alternative mayfly oviposition 618 behaviors. Behavioral Ecology and Sociobiology 61:1437-1448 doi: 10.1007/s00265-007-0376-4

619 Encalada AC, Peckarsky BL (2012) Large-scale manipulation of mayfly recruitment affects population size.

$620 \quad$ Oecologia 168:967-976 doi: 10.1007/s00442-011-2147-1

621 Fagan WF, Folarin A (2001) Contrasting scales of oviposition and parasitism in praying mantids. Popul.

$622 \quad$ Ecol. 43:87-96

623 Gabel B, Thiéry D (1992) Biological evidence of an oviposition-deterring pheromone in Lobesia botrana

624 Den. et Schiff. (Lepidoptera, Tortricidae). Journal of Chemical Ecology 18:353-358 doi:

$625 \quad 10.1007 / \mathrm{bf00994236}$

626 Gordon ND, McMahon TA, Finlayson BL, Gippel CJ, Nathan RJ (2004) Stream Hydrology: An Introduction

627 for Ecologists, Second edn. John Wiley \& Sons, Chichester, UK

628 Gripenberg S, Mayhew PJ, Parnell M, Roslin T (2010) A meta-analysis of preference-performance

629 relationships in phytophagous insects. Ecol. Lett. 13:383-393

630 Haddow AJ, Corbet PS (1961) Entomological studies from a high tower in Mpanga Forest, Uganda.

631 Transactions of the Royal Entomological Society of London 113:284-300 doi: doi:10.1111/j.1365-

$632 \quad$ 2311.1961.tb02288.x

633 Hassell MP, Pacala SW (1990) Heterogeneity and the dynamics of host—parasitoid interactions.

634 Philosophical Transactions of the Royal Society of London. Series B: Biological Sciences 330:203-220

635 Heard SB (1998) Resource patch density and larval aggregation in mushroom-breeding flies. Oikos 81:187-

636195 doi: $10.2307 / 3546480$

637 Hildrew AG, Wagner R (1992) The briefly colonial life of hatchlings of the net-spinning caddisfly

638 Plectrocnemia conspersa. J. N. Am. Benthol. Soc. 11:60-68 doi: 10.2307/1467882

639 Huffaker CB (1958) Experimental studies on predation: dispersion factors and predator-prey oscillations.

$640 \quad$ Hilgardia 27:343-383 doi: 10.3733/hilg.v27n14p343

641 Ives AR (1988) Aggregation and coexistence of competitors. Ann. Zool. Fenn. 25:75-88 
642 Ives AR (1991) Aggregation and coexistence in a carrion fly community. Ecol. Monog. 61:75-94 doi:

$643 \quad 10.2307 / 1943000$

644 Jones R (1977) Movement patterns and egg distribution in cabbage butterflies. The Journal of Animal

645 Ecology:195-212

646 Körösi Á, Örvössy N, Batáry P, Kövér S, Peregovits L (2008) Restricted within-habitat movement and time647 constrained egg laying of female Maculinea rebeli butterflies. Oecologia 156:455-464

648 Kouki J (1991) Tracking spatially variable resources: an experimental study on the oviposition of the water-

649 lily beetle. Oikos 61:243-249 doi: 10.2307/3545342

650 Lancaster J, Downes BJ (2004) Spatial pattern analysis of available and exploited resources. Ecography

$651 \quad 27: 94-102$ doi: $10.1111 / \mathrm{j} .0906-7590.2004 .03694 . x$

652 Lancaster J, Downes BJ (2013) Aquatic Entomology. Oxford University Press, UK

653 Lancaster J, Downes BJ (2014a) Maternal behaviours may explain riffle-scale variations in some stream

654 insect populations. Freshwater Biol. 59:502-513 doi: 10.1111/fwb.12281

655 Lancaster J, Downes BJ (2014b) Population densities and density-area relationships in a community with

656 advective dispersal and variable mosaics of resource patches. Oecologia 176:985-996 doi:

$657 \quad 10.1007 / \mathrm{s} 00442-014-3062-\mathrm{z}$

658 Lancaster J, Downes BJ (2018) Aquatic versus terrestrial insects: real or presumed differences in population 659 dynamics? Insects 9(4):157 doi: 10.3390/insects9040157

660 Lancaster J, Downes BJ, Arnold A (2010a) Environmental constraints on oviposition limit egg supply of a 661 stream insect at multiple scales. Oecologia 163:373-384 doi: 10.1007/s00442-010-1565-9

662 Lancaster J, Downes BJ, Arnold A (2010b) Oviposition site selectivity of some stream-dwelling caddisflies. 663 Hydrobiologia 652:165-178 doi: 10.1007/s10750-010-0328-2

664 Lancaster J, Downes BJ, Arnold A (2011) Lasting effects of maternal behaviour on the distribution of a 665 dispersive stream insect. J. Anim. Ecol. 80:1061-1069 doi: 10.1111/j.1365-2656.2011.01847.x 
666 Lancaster J, Downes BJ, Reich P (2003) Linking landscape patterns of resource distribution with models of 667 aggregation in ovipositing stream insects. J. Anim. Ecol. 72:969-978 doi: 10.1046/j.1365$668 \quad 2656.2003 .00764 . x$

669 Lancaster J, Glaister A (2019) Egg masses of some stream-dwelling caddisflies (Trichoptera: Hydrobiosidae) 670 from Victoria, Australia. Austral Entomology in press doi: 10.1111/aen.12360

671 Löfstedt C, Hansson BS, Petersson E, Valeur P, Richards A (1994) Pheromonal secretions from glands on the 6725 th abdominal sternite of hydropsychid and rhyacophilid caddisflies (Trichoptera). Journal of Chemical 673 Ecology 20:153-170 doi: 10.1007/BF02065998

674 Lounibos LP (1981) Habitat segregation among African treehole mosquitoes. Ecol. Entomol. 6:129-154 doi: $675 \quad 10.1111 / \mathrm{j} .1365-2311.1981 . t b 00601 . \mathrm{x}$

676 Mattingly WB, Flory SL (2011) Plant architecture affects periodical cicada oviposition behavior on native 677 and non-native hosts. Oikos 120:1083-1091

678 McPeek MA (2017) The ecological dynamics of natural selection: traits and the coevolution of community $679 \quad$ structure. Am. Nat. 189:E91-E117 doi: 10.1086/691101

680 Melnitsky S, Ivanov V (2011) Structure and localization of sensilla on antennae of caddisflies (Insecta: 681 682 683 684 685 Trichoptera). Journal of Evolutionary Biochemistry and Physiology 47:593-602

Menge BA (1976) Organization of the New England rocky intertidal community: role of predation, competition, and environmental heterogeneity. Ecol. Monog. 46:355-369 doi: 10.2307/1942563

Miller RS (1967) Pattern and process in competition. In: Cragg JB (ed) Adv. Ecol. Res., vol 4. Academic Press, pp 1-74

Morris WF, Wiser SD, Klepetka B (1992) Causes and consequences of spatial aggregation in the phytophagous beetle Altica tombacina. J. Anim. Ecol.:49-58 doi: 10.2307/5508.

Neboiss A (1986) Atlas of Trichoptera of the SW Pacific-Australia region. Dr W. Junk, Dordrecht, The Netherlands

Peckarsky BL, Taylor BW, Caudill CC (2000) Hydrologic and behavioral constraints on oviposition of stream insects: implications for adult dispersal. Oecologia 125:186-200 doi: 10.1007/s004420000446 
692 R Core Development Team (2017) R: A language and environment for statistical computing. R Foundation 693 for Statistical Computing, Vienna, Austria

694 Refsnider JM, Janzen FJ (2010) Putting eggs in one basket: Ecological and evolutionary hypotheses for 695 variation in oviposition-site choice. Annu. Rev. Ecol. Evol. S. 41:39-57 doi: 10.1146/annurev-ecolsys$696 \quad 102209-144712$

697 Reich P (2002) The egg masses of lotic invertebrates: proximate cues for oviposition site selection and 698 implications for larval abundance and distribution. Ph.D. Thesis, The University of Melbourne, Victoria, $699 \quad$ Australia

700 Reich P (2004) Patterns of composition and abundance in macroinvertebrate egg masses from temperate 701 Australian streams. Mar. Freshwater Res. 55:39-56 doi: 10.1071/MF03129

702 Reich P, Downes BJ (2003a) The distribution of aquatic invertebrate egg masses in relation to physical 703 characteristics of oviposition sites at two Victorian upland streams. Freshwater Biol. 48:1497-1513 doi: 704 705

Reich P, Hale R, Downes BJ, Lancaster J (2011) Environmental cues or conspecific attraction as casues for egg mass aggregation in hydrobiosid caddisflies. Hydrobiologia 661:351-362 doi: 10.1007/s10750-010$0543-\mathrm{x}$

Renwick JAA, Chew FS (1994) Oviposition behavior in Lepidoptera. Annu. Rev. Entomol. 34:377-400 doi: 10.1146/annurev.en.39.010194.002113

Resetarits Jr. WJ (2001) Colonization under threat of predation: avoidance of fish by an aquatic beetle, Tropisternus lateralis (Coleoptera: Hydrophilidae). Oecologia 129:155-160 doi: 10.1007/s004420100704 Resh VH, Wood JR (1985) Site of sex pheromone production in three species of Trichoptera. Aquatic Insects 7:65-71 doi: 10.1080/01650428509361202

Ripley BD (1976) The second-order analysis of stationary processes. J. Appl. Prob. 13:255-266 doi: $10.2307 / 3212829$ 
718 Schoonhoven LM, Beerling EAM, Klijnstra JW, van Vugt Y (1990) Two related butterfly species avoid

719 oviposition near each other's eggs. Experientia 46:526-528 doi: 10.1007/bf01954255

720 Schtickzelle N, Joiris A, Van Dyck H, Baguette M (2007) Quantitative analysis of changes in movement

721 behaviour within and outside habitat in a specialist butterfly. BMC Evolutionary Biology 7:4

722 Schultz CB, Franco AM, Crone EE (2012) Response of butterflies to structural and resource boundaries. J.

723 Anim. Ecol. 81:724-734

724 Southwood TRE (1978) Ecological Methods, 2nd edition. Chapman and Hall, London

725 Städler E (2002) Plant chemical cues important for egg deposition by herbivorous insects. In: Hilker M,

726 Meiners T (eds) Chemoecology of Insect Eggs and Egg Deposition. Blackwell Science, Berlin, pp 171-

$727 \quad 204$

728 Vertacnik KL, Linnen CR (2017) Evolutionary genetics of host shifts in herbivorous insects: insights from

729 the age of genomics. Annals of the New York Academy of Sciences 1389:186-212

730 Warren-Rhodes KA, Dungan JL, Piatek J, Stubbs K, Gómez-Silva B, Chen Y, McKay CP (2007) Ecology

731 and spatial pattern of cyanobacterial community island patches in the Atacama Desert, Chile. Journal of

732 Geophysical Research: Biogeosciences, vol. 112, p G04S15

733 With KA, King AW (1997) The use and misuse of neutral landscape models in ecology. Oikos 79:219-229

734 doi: $10.2307 / 3546007$

735 
Table 1 Apsilochorema: Summary of MANOVA with planned contrasts in each of the three rivers. For nonsignificant interaction terms (Snobs Ck, Steavenson R.), the presence/absence test for each species indicates whether rocks with and without EMs differ; for a significant interaction term (Little R.) then pairwise contrasts provide this test. In all rivers, planned contrasts indicate whether environmental characteristics of the ERs used for oviposition differed between the two species.

\begin{tabular}{|c|c|c|c|c|c|}
\hline River & Source & $\mathrm{df}$ & $\begin{array}{l}\text { Pilai's } \\
\text { trace }\end{array}$ & $F$ & $P$ \\
\hline \multirow[t]{4}{*}{ Snobs Ck } & Presence/absence $A$. obliquum & 4,554 & 0.025 & 3.55 & 0.007 \\
\hline & Presence/absence $A$. gisbum & 4,554 & 0.014 & 1.97 & 0.098 \\
\hline & Interaction & 4,554 & 0.010 & 1.37 & 0.244 \\
\hline & A. obliquum vs A. gisbum & 4,554 & 0.013 & 1.88 & 0.113 \\
\hline \multirow[t]{6}{*}{ Little R. } & Presence/absence $A$. obliquum & 4,2057 & 0.034 & 17.8 & $<0.001$ \\
\hline & Presence/absence $A$. gisbum & 4,2057 & 0.020 & 10.5 & $<0.001$ \\
\hline & Interaction & 4,2057 & 0.008 & 4.32 & 0.002 \\
\hline & A. obliquum vs no eggs & 4,2057 & 0.050 & 27.3 & $<0.001$ \\
\hline & A. gisbum vs no eggs & 4,2057 & 0.029 & 15.4 & $<0.001$ \\
\hline & A. obliquum vs A. gisbum & 4,2057 & 0.003 & 1.70 & 0.146 \\
\hline \multirow[t]{4}{*}{ Steavenson R. } & Presence/absence $A$. obliquum & 4,1748 & 0.016 & 6.88 & $<0.001$ \\
\hline & Presence/absence $A$. gisbum & 4,1748 & 0.022 & 9.99 & $<0.001$ \\
\hline & Interaction & 4,1748 & 0.000 & 0.189 & 0.944 \\
\hline & A. obliquum vs A. gisbum & 4,1748 & 0.002 & 0.850 & 0.494 \\
\hline
\end{tabular}


Table 2 Ulmerochorema: Summary of MANOVA in each of the three rivers showing the overall multivariate test and planned contrasts, which compared exploited and unexploited ERs for each species, and compared exploited ERs of the two species.

\begin{tabular}{|c|c|c|c|c|c|}
\hline River & Source & $\mathrm{df}$ & $\begin{array}{l}\text { Pilai's } \\
\text { trace }\end{array}$ & $F$ & $P$ \\
\hline \multirow[t]{4}{*}{ Snobs Creek } & Multivariate test & 8,1102 & 0.277 & 22.2 & $<0.001$ \\
\hline & U. rubiconum vs no eggs & 4,551 & 0.931 & 1850 & $<0.001$ \\
\hline & U. seona vs no eggs & 4,551 & 0.873 & 948 & $<0.001$ \\
\hline & U. rubiconum vs $U$. seona & 4,551 & 0.13 & 20.6 & $<0.001$ \\
\hline \multirow[t]{4}{*}{ Little River } & Multivariate test & 8,4118 & 0.248 & 72.8 & $<0.001$ \\
\hline & U. rubiconum vs no eggs & 4,2058 & 0.928 & 6664 & $<0.001$ \\
\hline & U. seona vs no eggs & 4,2058 & 0.875 & 3606 & $<0.001$ \\
\hline & U. rubiconum vs $U$. seona & 4,2058 & 0.101 & 57.6 & $<0.001$ \\
\hline \multirow[t]{4}{*}{ Steavenson River } & Multivariate test & 8,3498 & 0.284 & 72.3 & $<0.001$ \\
\hline & U. rubiconum vs no eggs & 4,1748 & 0.915 & 4702 & $<0.001$ \\
\hline & U. seona vs no eggs & 4,1748 & 0.787 & 1614 & $<\mathbf{0 . 0 0 1}$ \\
\hline & U. rubiconum vs $U$. seona & 4,1748 & 0.055 & 25.3 & $<0.001$ \\
\hline
\end{tabular}


Table 3 Summary of univariate point pattern analyses: the number of riffles in each river that provided evidence of random or clumped spatial patterns of exploited ERs for each species, relative to the background pattern of suitable ERs. Even distribution patterns did not occur. Only riffles with enough ERs and EMs were used (ESM-5, see text for explanation). In only one riffle were ERs exploited by Ulmerochorema seona sufficiently abundant for these analyses.

\begin{tabular}{|c|c|c|c|}
\hline Species & River & Random & Clumped \\
\hline \multirow[t]{3}{*}{ U. rubiconum } & Snobs & 0 & 2 \\
\hline & Little & 2 & 4 \\
\hline & Steavenson & 1 & 3 \\
\hline U. seona & Little & 0 & 1 \\
\hline \multirow[t]{2}{*}{ A. obliquum } & Little & 4 & 1 \\
\hline & Steavenson & 3 & 0 \\
\hline \multirow[t]{3}{*}{ A. gisbum } & Snobs & 1 & 0 \\
\hline & Little & 3 & 1 \\
\hline & Steavenson & 1 & 1 \\
\hline
\end{tabular}


Table 4 For each species and river, summary of G-tests for goodness-of-fit tests of EM frequency data to zero-truncated Poisson distribution. Under-dispersed pattern $=$ more rocks with a single egg mass than expected by chance; aggregated = more rocks with very many egg masses than expected by chance. df varied between tests because some frequency categories had to be combined to ensure expected frequencies $>5$ for each category, as typically required for goodness-of-fit tests.

\begin{tabular}{llllll}
\hline Species & Site & $\mathrm{G}_{\mathrm{adj}}$ & $\mathrm{df}$ & \multicolumn{1}{c}{$P$} & Pattern \\
\hline Apsilochorema obliquum & Snobs Ck & 3.22 & 2 & 0.200 & random \\
& Little R. & 17.1 & 3 & $<\mathbf{0 . 0 0 1}$ & under-dispersed \\
& Steavenson R. & 1.69 & 2 & 0.429 & random \\
Apsilochorema gisbum & Snobs Ck & 11.1 & 3 & $\mathbf{0 . 0 1 1}$ & under-dispersed \\
& Little R. & 21.6 & 3 & $<\mathbf{0 . 0 0 1}$ & under-dispersed \\
& Steavenson R. & 1.58 & 2 & 0.454 & random \\
Ulmerochorema rubiconum & Snobs Ck & 594 & 5 & $<\mathbf{0 . 0 0 1}$ & aggregated \\
& Little R. & 617 & 5 & $<\mathbf{0 . 0 0 1}$ & aggregated \\
& Steavenson R. & 235 & 8 & $<\mathbf{0 . 0 0 1}$ & aggregated \\
& Snobs Ck & 100 & 3 & $<\mathbf{0 . 0 0 1}$ & aggregated \\
& Little R. & 90.9 & 4 & $<\mathbf{0 . 0 0 1}$ & aggregated \\
& Steavenson R. & 6.60 & 2 & $\mathbf{0 . 0 3 7}$ & aggregated \\
& & & & & \\
\hline Ulmerochorema seona & & & & &
\end{tabular}




\section{FIGURE LEGENDS}

Fig. 1. Examples of cumulative frequencies of emergent rocks according to four environmental variables (velocity, water depth, rock size, exposed height of rock) for Apsilochorema spp. in the Steavenson River (top panels), and for Ulmerochorema spp. in the Little River (bottom panels). Similar patterns were found in all rivers, but have been omitted for brevity. In most cases, the cumulative frequencies of exploited ERs lie to the right of the lines for unexploited ERs. This indicates that the proportions of exploited ERs with low values of each environmental variable were lower than their relative abundance in the set of unexploited ERs

Fig. 2. Examples of maps and point pattern analysis of ERs exploited by (a) and (b) Ulmerochorema rubiconum (Little R. riffle 7), and by (c) and (d) Apsilochorema obliquum (Little R. riffle 3). Maps in (a) and (c) are drawn to the same scale and oriented with water flowing from right to left. Solid lines represent the wetted channel width, dashed lines the up- and downstream extent of the surveyed riffle. Point pattern analyses illustrating (b) a clumped distribution of ERs exploited by U. rubiconum and (d) a random distribution of ERs exploited by A. obliquum. Solid line indicates the mean difference between the observed $L I$-function and the $L I$-function of a random selections of suitable rocks, dotted lines indicate $95 \%$ global confidence envelope for this difference, dashed lines indicate the null hypothesis of no difference. Patterns at small values of $t$ (within the grey area) were ignored when assessing the kind of distribution patterns (see text for explanation: Results (Q2))

Fig. 3. Co-occurrence of different species' egg masses on oviposition sites: (a) and (b) Proportion of all exploited ERs that had egg masses of only one species or both congers of (a) Apsilochorema and (b) Ulmerochorema. Bars represent means \pm SE of the different rivers. (c) and (d) Sørenson's coefficient of association (mean \pm SE) between congeners of (c) Apsilochorema and (d) Ulmerochorema in each river. Values $<0$ suggest negative association; values $>0$ suggest positive association. $\mathrm{N}=$ number of riffles per river used to calculate the mean. No data for Steavenson River in (d) because U. seona were too scarce for meaningful analysis. Statistically, 
Sørenson's coefficient did not differ among rivers for either genus (Apsilochorema: $F_{2,16}=1.09, P$ $=0.363$; Ulmerochorema: $\left.F_{1,10}=0.038, P=0.849\right)$. Combining data across rivers, the index was significantly less than zero for Apsilochorema $\left(t_{16}=4.84, P<0.001\right)$, but did not differ from zero 